\title{
Response: Population Health Approaches to First Aid Training-- A Critical Need
}

I always marvel at the growing capacity of our emergency response, trauma care, and reconstructive systems to save lives and return people to amazing levels of function after significant and often life threatening illness or injury. I am also amazed at the lack of diffusion of this capacity worldwide. Saving lives through a well-structured system of emergency care is something we know how to do and where we have an overwhelming amount of evidence that it is effective. How then have we as a society failed to ensure its adoption on a population basis everywhere.

This is also true around the capacity at the very basic level first aid. While we clearly have well-established programs in first aid, it is clear that that ensuring the capacity and skill levels across the population worldwide remains elusive. Jeffrey Pellegrino and his colleagues argue in this issue of the International Journal of First Aid Education that we need to rethink the education of first aid through a lens of achieving population health through a prevention model. Such a model would mean that preventing many emergencies from happening in the first place is at the very core of emergency care. It is an interesting concept; one that would be a major thought shift in emergency care and would redefine the goal of reducing morbidity, mortality and long term disability not in a response capacity after it happens but through mitigation and then response when needed.

Far too often, the social situation of the individual and their family is not taken into consideration from the emergency response perspective. The Chain of Survival Behaviors promotes first aid providers to address injury prevention after providing initial care. For example, after a fall individual first aiders or first aid organizations might engage the family or population to address other fall hazards. Another example might be for first responders to be trained to engage with the local public health agency to address the social determinants of health before the summer heat wave or other severe environmental conditions. This work addresses major causes of heart attacks and strokes objectively, but also can be the catalyst for stopping a potential emergency before any first aid action is needed.

As an emergency physician that has made the transition from emergency care to public health, this concept is of great interest and could serve as the foundation of moving emergency care well upstream in practice. This would require building a population based approach into the curriculum of first aid, as well 
as metrics on how best to achieve competency and retention. Dr. Pellegrino and his colleagues have raised a most interesting question on how to, as they call it, "a call for revolution in first aid education." I think it is an interesting idea that has merit and should be further explored.

Georges C. Benjamin, Executive Director

American Public Health Association 